\title{
Economic Shocks and the Fed's Policy--The Transmission Conduit and Its International Linkage
}

\author{
Jen-Chi Cheng ${ }^{1} \&$ Chu-Ping C. Vijverberg ${ }^{1}$ \\ ${ }^{1}$ Barton School of Business, Wichita State University, USA \\ Correspondence: Jen-Chi Cheng, Department of Economics, Wichita State University, Wichita, KS 67260-0078, \\ USA. Tel: 1-316-978-7084. E-mail: jenchi.cheng@wichita.edu
}

Received: May 4, 2012

doi:10.5539/ijef.v4n8p12
Accepted: June 4, 2012

Online Published: July 2, 2012

URL: http://dx.doi.org/10.5539/ijef.v4n8p12

\begin{abstract}
This paper uses a Bayesian Vector Autoregression (BVAR) model to evaluate the impacts of policy and financial shocks on several economic variables. We use both expected federal funds and unexpected federal funds rates as an indicator of monetary policy respectively.In addition to the traditional financial market measures, i.e., bank loan and equity price changes to signal the financial shocks, we introduce a new credit measure that reflects the differential credit access for small and large firms. We use U.S. monthly data from July 1954 to March 2009.The results of our impulse response functions and variance decomposition provide a positive assessment of the Fed's recent policy actions. We also extend the framework to include four foreign countries and show that foreign stock prices are significantly affected by U.S. equity shock in a later time period, indicating a stronger global integration recently.Nevertheless, the U.S. equity market is not affected much by the foreign equity market.
\end{abstract}

Keywords: bayesian regression, monetary transmission mechanism, impulse response function, variance decomposition, policy reaction function

\section{Introduction}

The current recession that began in December 2007 has brought monetary policy back to the center stage of policy making and research.Since the recession was caused by a mortgage-housing-leverage crisis and its ensuing credit freeze, the Fed's main strategy was to ease terms of credit and to prevent economic damage from systemic liquidity risk.The Fed has focused its policy on two fronts.First, the federal funds rate has been changed ten times, lowered from 5.25\% in September 2007 to $0-0.25 \%$ in December 2008 and held at that rate ever since.Second, the Fed has taken a non-traditional step to lend directly to financial firms and purchase commercial papers from them, conforming mortgages and securities of consumer and small business loans. This direct lending aims to soften the freeze in the credit crunch so the economy can survive the crisis without severe damage.Despite all the aggressive efforts by the Fed, bank lending fell by $\$ 587$ billion, or $7.5 \%$, in 2009 , the largest annual decline since the 1940s. The FDIC considers 702 out of the nation's 8012 banks to be at the risk of failure. (Note 1)The number grew to 888, a historical high, at the end of 2010 and then slipped to 813 in the fourth quarter of 2011. In the equity market, investors pushed the Standard \& Poor's 500 from around 1,500 in December 2007 to 676.53 on March 9, 2009, the lowest level since 1996. The stock market has recovered to some extent, and the index stood at around 1,100 in July 2010 and 1,350 in March 2012.The ongoing monetary policy "experiment" and its interactions with the financial markets have prompted a time-honored yet intriguing question: how effective are the Fed's policy actions?

An inquiry into the efficacy of the Fed's actions naturally brings forth the issue of the mechanism through which the policy is transmitted (or channeled).This continues to be a challenging issue for financial economists as well as policy makers perhaps mostly due to the changing dynamics of financial market and the evolving instruments. This paper focuses on two possible channels: credit channel and equity channel.The effectiveness of the credit channel hinges on two links: first, the Fed's actions and bank loans; second, bank loans and the real economy.The new policy tool that the Fed used recently to lend directly to firms (i.e., increase loan availability in the economy directly) ensures the effectiveness of the first linkage.The efficacy of the Fed's policy thus centers on whether the supply of bank loans has a real effect.The literature appears mixed in its findings (Kashyap and Stein, 1994, 2000; Oliner and Rudebusch, 1996; Driscoll, 2004).One explanation for the findings of ineffectiveness in the second linkage (i.e., between bank loans and real output) is that not all firms are 
bank-dependent (Driscoll, 2004).For instance, large firms can substitute other forms of finance such as bond or equity financing for bank loans.Thus, bank loans alone may not measure credit conditions appropriately.This view is implied in the financial accelerator model but with a different twist (Hubbard, 1995; Bernanke et al., 1996; Gertler and Gilchrist, 1993; Vijverberg, 2004).The financial accelerator mechanism works through bank-dependent small firms. Since small firms are more dependent on bank loans, they are more sensitive to loan availability and market interest rates.Campello, Graham, and Harvey (2010) extend this line of research by studying credit constraints experienced by nonfinancial firms.In December 2008, they asked 1,050 chief financial officers in 39 countries in Asia, Europe and North America whether they experienced a credit constraint and how they responded during the crisis. The authors discovered that in the United States, 325 of the 569 surveyed firms were somewhat or very affected by a credit constraint.In the overall sample, the constrained firms cut the number of employees 11 percent, more than the 7 percent by the non-constrained firms.These studies evidently show that actions of the Fed may impact bank loan availability and affect firms' expenditures and therefore influence aggregate economic activity.

The argument for monetary transmission through an equity channel can easily find its support from a recent stock market surge caused by Bernanke's surprising remarks at a national conference on maintaining a low interest rate policy. (Note 2)The equity channel is based on Tobin's q-theory (Tobin, 1969).Tobin's q is the ratio of market value of the firm over its replacement cost. When q is greater (less) than one, investment spending is likely to increase (decrease) because it is cheaper (more expensive) to build new factories. When working through the equity channel, a monetary shock or disturbance is expected to change the present value of future earnings. The change in equity (or stock) price implies a change in Tobin's q, which subsequently could affect aggregate spending of the economy.Bernanke and Kuttner (2005) believe that monetary policy has its most direct and immediate effects on the more broadly defined financial market such as the stock market.They point out that the market is unlikely to respond to expected policy changes, suggesting an inevitability to distinguish between expected and unexpected policy actions.Using the CRSP value-weighted index, they find that an unexpected 25-basis-point rate cut leads to a one percent increase in stock prices.

This paper seeks to evaluate policy actions of the Fed empirically and at the same time measure the impact of different economic and financial shocks to key macroeconomic variables. (Note 3)This paper contributes to the literature in three aspects.First, in addition to the traditional credit measure, it applies a new credit measure to reflect the differential access between large firms and small firms.Both credit measures are used to evaluate the two linkages in the credit channel.Given the Fed's policy actions in 2008-2009, it is interesting to see what has happened to the second linkage, i.e., the impact of a credit measure shock on the real economy.This could be used to validate the financial accelerator mechanism.Second, this paper uses both the federal funds rate (ffr) and the unexpected federal funds rate (u.ffr) as indicators of monetary policy.While many event studies such as Ehrmann and Fratzscher (2004) and Bernanke and Kuttner (2005) examine the responses of an unexpected federal funds rate shock on a "daily" basis, this paper uses monthly data.In doing so, we do recognize the possibility that significant responses in higher frequency data may not be captured in lower frequency data.Third, besides measuring the impact of a U.S. equity shock on the U.S. economy, the ever-increasing trend of globalization makes it essential to study the impact of a U.S. equity shocks on foreign equity markets also.In fact, the recent world-wide recession was triggered by the U.S.Even though the Fed cannot manipulate the equity market directly, its policies could change investor confidence and disturb or restore financial stability.For instance, a favorable shock to the equity market may help reduce the unemployment rate in the long run, coincidentally a finding of this paper.The degree of correlation between the American equity market and its foreign counterparts will certainly determine the extent to which the Fed's policy of stabilizing the U.S. equity market helps other economies as well.

To study these policy issues, this paper will apply a Bayesian Vector Autoregression (BVAR) model previously developed by Sims and Zha (1998) and Waggoner and Zha (2003). This BVAR model is briefly discussed in the next section.Section 3 describes the data, and Section 4 presents empirical BVAR estimates of the impulse response functions and variance decompositions.Section 5 extends the research to a set of foreign countries and examines the impact of U.S. monetary policy on foreign share prices.The effect of a shock in the U.S. equity market on the foreign equity markets is also examined.Section 6 closes the paper with concluding remarks.

\section{A Bayesian VAR Model}

A VAR model with many variables and long lags has lots of parameters.Estimation of these VAR parameters requires a lot of data and the forecasts of the model may be imprecise because of over-parameterization.Bayesian VAR models differ from traditional VAR models by treating the model parameters as random variables. The posterior distributions of these random (parameter) variables derive from the prior and the likelihood of the 
data.In contrast to the traditional VAR model, which does not incorporate non-sample information, Bayesian VAR integrates researchers' prior (non-sample) belief. (Note 4) Furthermore, the distribution of the prior that is comprised in a few hyper-parameters reduces the number of parameters directly, which addresses the issue of over-parameterization in traditional VAR models. This enhances the forecast precision of a Bayesian model.In this paper, we will use a BVAR model.

Our model is formulated as the following.Note that, to distinguish between vectors and matrices, a variable with an underscore is a vector and a variable without an underscore is a matrix.

$$
\underline{y_{t}^{\prime}} \cdot A_{0}=\underline{c}_{0}+\sum_{i=1}^{p} \underline{y}_{t-i}^{\prime} \cdot A_{i}+\varepsilon_{t}^{\prime}
$$

for $t=1 \ldots . . T$ and $i=1, \ldots p$; where $\underline{y}_{t-i}$ is an $m \times 1$ vector of an $m$-variable observation at $t-i, \underline{c}_{0}$ is a $1 \times \mathrm{m}$ vector, $\underline{a}_{0} \underline{\varepsilon}_{t}$ is an $\mathrm{m} \times 1$ vector, $A_{i}$ are $m \times m$ parameter matrices, $p$ is the lag length and $T$ is the total number of observations.

The disturbances have a Gaussian distribution with $E\left(\underline{\varepsilon}_{t} \mid \underline{\Lambda}_{t}\right)=\underline{0}$ and $\operatorname{Var}\left(\underline{\varepsilon}_{t} \mid \underline{\Lambda}_{t}\right)=\underline{I}$ where $\underline{\Lambda}_{t}$ is information up to $t$-1.The above equation can be restated as the following:

$$
Y \cdot A_{0}=X \cdot F+E
$$

where both $Y$ and $\mathrm{E}$ are $T \times m$ matrices, $\mathrm{X}$ is a $T \times m(p+1)$ matrix with each row being $\left[\underline{c}_{0}, \underline{y}_{t-1}^{\prime}, \ldots, \underline{y}_{t-p}^{\prime}\right]$ and $F^{\prime}=\left[I, A_{1}^{\prime}, A_{2}^{\prime}, \ldots, A_{p}^{\prime}\right]$ is an $m \times m(p+1)$ matrix. $\mathrm{F}$ will be referred to as the lagged parameters. The corresponding reduced form VAR has a reduced form variance matrix of $\Sigma$ where $\Sigma=\left(A_{0} A_{0}^{\prime}\right)^{-1}$.

A Bayesian model consists of two major elements: the likelihood function and the prior.The likelihood function in this model is $L\left(Y \mid A_{0}, F\right) \propto\left|A_{0}\right|^{T} \exp \left[-0.5\left(Y A_{0}-X F\right)^{\prime}\left(Y A_{0}-X F\right)\right]$. The prior comes in the form of a probability density function. There are various ways to set up the prior (Sims and Zha, 1998). A brief description of this prior will be given here. Let $A=\left(A_{0}, F\right), \underline{a}=\operatorname{vec}(A)$ and $\underline{\mathrm{f}}=\operatorname{vec}(F)$ where vec is the vectorization operator.Based on Sims and Zha (1998), the matrix $A$ has a prior pdf of $\pi(\underline{a})=\pi_{0}\left(\underline{a}_{0}\right) \cdot \phi\left(E\left(\underline{\mathrm{f}} \mid \underline{a}_{0}\right) ; \psi\right)$ where $\pi_{0}\left(\underline{a}_{0}\right)$ is a marginal distribution of $\underline{a}_{0}$ and $\phi(. ., \psi)$ is a conditional distribution off conditioning on $\underline{a}_{0} ; \phi(. ., \psi)$ is also a normal pdf with a covariance matrix $\psi$. In Sims and Zha (1998), specific restrictions are imposed on these two distributions such that the corresponding prior on the reduced form parameters is similar to Litterman's random walk prior. That implies that $E\left(\underline{\mathrm{f}} \mid \underline{a}_{0}\right)=\left[\underline{a}_{0}^{\prime}, \underline{0}^{\prime}\right]$ and $\operatorname{Var}\left(\underline{\mathrm{f}} \mid \underline{a}_{0}\right)=\psi$, where $\psi$ is the conditional covariance prior for $F$. Each diagonal element of $\psi$ corresponds to the variance of the VAR parameter.Each variance has the following form: $\hat{S}_{l, j, i}=\left(\lambda_{0} \lambda_{1} / \sigma_{j} l^{\lambda 3}\right)^{2}$, which is for the $l^{\text {th }}$ lag of variable $j$ in equation $i$; and $\sigma_{j}^{2}$ is the value of error variances from a univariate $\operatorname{AR}(p)$ OLS regression of the $j^{\text {th }}$ variable on its own lags. These various $\lambda_{i} s$ are referred to as hyper-parameters. The choice of these $\lambda_{i} s$ is equivalent to the choice of prior in the model. (Note 5) Combining the prior with the likelihood function, we may obtain the following posterior distribution: $q(\underline{a}) \propto$ $p\left(\underline{a}_{0} \mid Y\right) \cdot p\left(\underline{f} \mid \underline{a}_{0}, Y\right)$. Thus, besides conditioning on the data, the joint posterior distribution contains two parts: the marginal distribution of $\underline{a}_{0}$ and the conditional distribution of $\underline{\underline{f}}$ conditioning on $\underline{a}_{0}$ (for a more detailed distributional form, see Waggoner and Zha (2003)).

\section{Key Variables and Sample Selection}

\subsection{The Policy Variables}

To choose a proxy for the monetary policy, the selection varies from non-borrowed reserves (Christiano and Eichenbaum, 1992), borrowed reserves (Cosimano and Sheehan, 1994), the percentage of non-borrowed reserves (Strongin, 1995), and the federal funds rate (Bernanke and Blinder, 1992). When tested together with borrowed and non-borrowed reserves (Bernanke and Mihov, 1998), the federal funds rate appears to be an effective policy 
proxy.Thus, we will use the federal funds rate (ffr) as an indicator of monetary policy. Nevertheless, Bernanke and Kuttner (2005) pointed out that, to have more discerning equity price responses, it is essential to distinguish between expected and unexpected policy actions because the stock market is unlikely to respond to policy actions that are already anticipated.We will thus also use the unexpected federal funds rate (u.ffr) as an indicator of the policy action.However, this u.ffr can only be constructed for a specific time period.

Even so, it is not straightforward to construct u.ffr.In the literature, there are three ways to identify the unexpected monetary policy action. The difference in these varying methods lies in the derivation of the expected federal funds rate.The u.ffr is defined as the difference between the actual federal funds rate and the expected federal funds rate.The most frequently used method in the literature derives the expected federal funds rate from federal funds futures contracts (Kuttner 2001; Bernanke and Kuttner, 2005).The second method derives its expectation from surveys of market participants (Ehrmann and Fratzscher, 2004).The third method uses the Taylor rule to derive the expected federal funds rate (Konrad, 2009).The first two techniques are suitable for event studies.Since we use BVAR, we will use the Taylor rule to calculate the market expectations of the ffr and the monetary shock.

We follow Konrad (2009) in deriving our expected ffr.Based on Monetary Trend, a publication of the St. Louis Federal Reserve, the expected ffr $\left(f_{t}^{e}\right)$ implied by the Taylor rule is defined as follows:

$$
f_{t}^{e}=r^{*}+\pi_{t-1}+0.5 \times\left(\pi_{t-1}-\pi^{*}\right)+0.5 \times\left(y_{t-1}-y_{t-1}^{p}\right) \times 100
$$

where $r^{*}$ is the equilibrium short-term interest rate at time $t, \pi_{t-1}$ is the previous period's inflation rate on a year-over-year basis, $\pi^{*}$ is the target inflation rate, $y_{t-1}$ is the log of previous period's output and $y_{t-1}^{p}$ is the $\log$ of the previous period's potential output.Prior to its April 2000 issue, Monetary Trend reported an inflation rate that was measured by CPI.Since then, the CPI inflation rate has been switched to PCE.This paper follows the same convention practiced by the St. Louis Fed, except that we calculate monthly implied ffr instead of quarterly implied rates.In addition, we set $\pi^{*}$ at $3 \%$ and $r^{*}$ at $2 \%$. (Note 6) To obtain monthly potential output, we apply the "disaggregate" function with cubic spline interpolation of S+FinMetrics to convert data from quarterly to monthly.The quarterly real actual and real potential GDP data are available from the St. Louis Fed.

The unexpected component of $\mathrm{ffr}\left(f_{t}^{u}\right)$ is calculated in the following manner:

$$
f_{t}^{u}=f_{t}^{a}-f_{t}^{e}
$$

where $f_{t}^{a}$ is the average monthly target ffr. (Note 7)Figure 1 shows the movements of each element of the ffr, i.e., $f_{t}^{a}, f_{t}^{e}$, and $f_{t}^{u}$.To check the validity of using the Taylor rule to reflect market expectations of the ffr, we follow the hypothesis of rational expectations, which assumes that the unexpected or the shock component of the ffr should have an expected value of zero, and apply the following regression:

$$
f_{t}^{a}=\beta_{0}+\beta_{1} f_{t}^{e}+\epsilon
$$

where an $\mathrm{F}$ test is used to test the null hypothesis $H_{0}: \beta_{0}=0$ and $\beta_{1}=1$. Using data from 1987:06-2009:03, we obtained a $p$-value of 0.0934 .Thus, at $5 \%$ significance level, we fail to reject the null and the hypothesis of rational expectations is confirmed. 


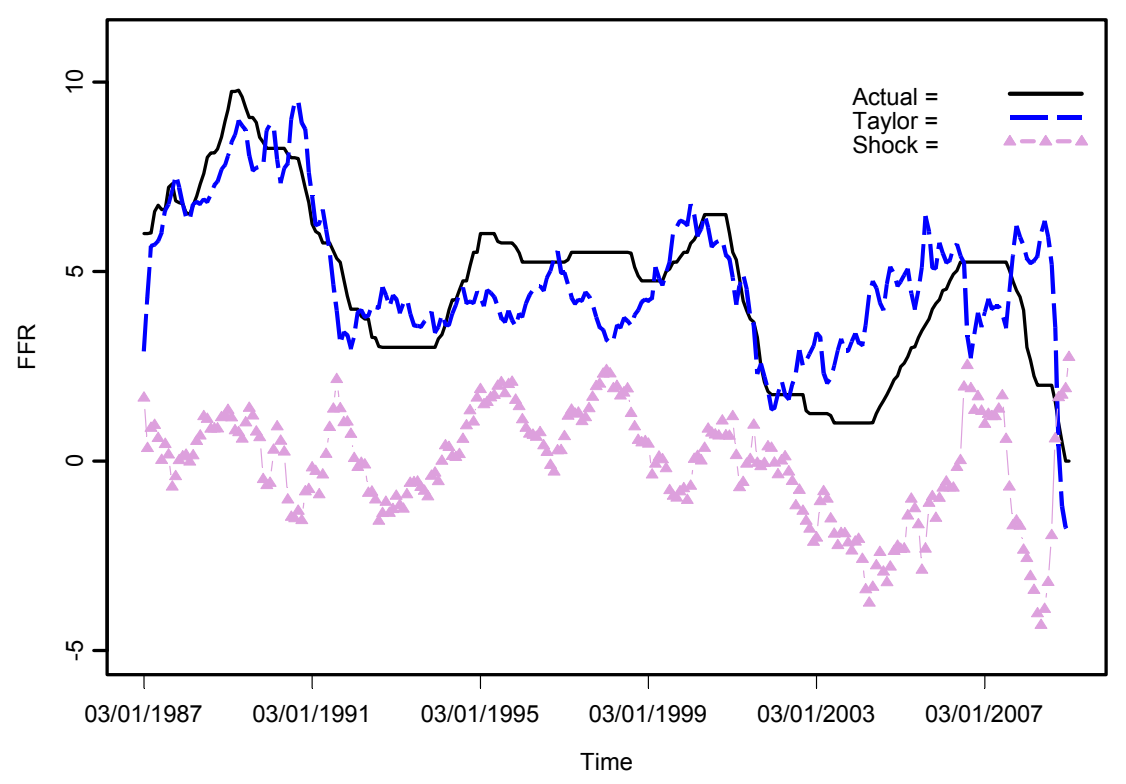

Figure 1. The Actual, Taylor-implied, and Shock Components of FFR

\subsection{Indicators of Credit Market Condition}

A standard indicator of credit market conditions is the percentage change in commercial and industrial bank loans.This data are obtained from the Federal Reserve of St. Louis.In addition to this standard indicator, we will adopt another indicator of credit markets that derives from the literature of "financial accelerator models" (Vijverberg, 2004). (Note 8)This indicator signals a differential access to credit between large firms and small firms.We use data from U.S. Flow of Funds tables L.102 and F.102 to demonstrate the relevance of this indicator.These are data of non-farm non-financial corporate business.Loans include business loans and other loans while bonds are corporate bonds.Figure 2 shows the growth rates of three measures of credit.The solid line is "p.loan", which is the percentage change of loans. The dashed line is "p.bond" which is the percentage change of corporate bonds.The line with " $\mathbf{\Delta}$ " is "c.index, which is calculated as "p.loan" minus "p.bond".As mentioned, this "c.index" indicates differential credit accessibility for small and large firms. When credit is tightened and banks do not want to lend, small firms' credit is rationed while large firms can still tap into credit markets by issuing corporate bonds.As shown in Figure 2, in each of the last three recessions (1991, 2001 and 2008), bank loans (i.e., "p.loan") dropped significantly while corporate bonds (i.e., "p.bond") still had positive changes. This "c.index" thus measures the credit availability for small firms, given that large firms may issue bonds at any time.A large (small) value of c.index implies easy (tight) loan access for small firms. This variable can be used to validate the financial accelerator mechanism that differential credit accessibility indeed matters in the monetary policy transmission conduit.

All data are seasonally adjusted monthly data.In addition to the c.index mentioned earlier, all data were downloaded from the Federal Reserve Bank of St. Louis except the SP500 index, which comes from Thomas Reuters' Interactive Data Real Time Services.The data we use in this paper, i.e., 1954:07-2009:03, covers a long time period.Since the U.S. economy has gone through many changes in regulations and restructuring, we will look into three different time periods: one whole period(1954:07 -2009:03), (Note 9)and two sub-periods(1954:07-1978:12) and (1987:06 -2009:03). (Note 10) Note that u.ffr is only available for the second sub-period. 


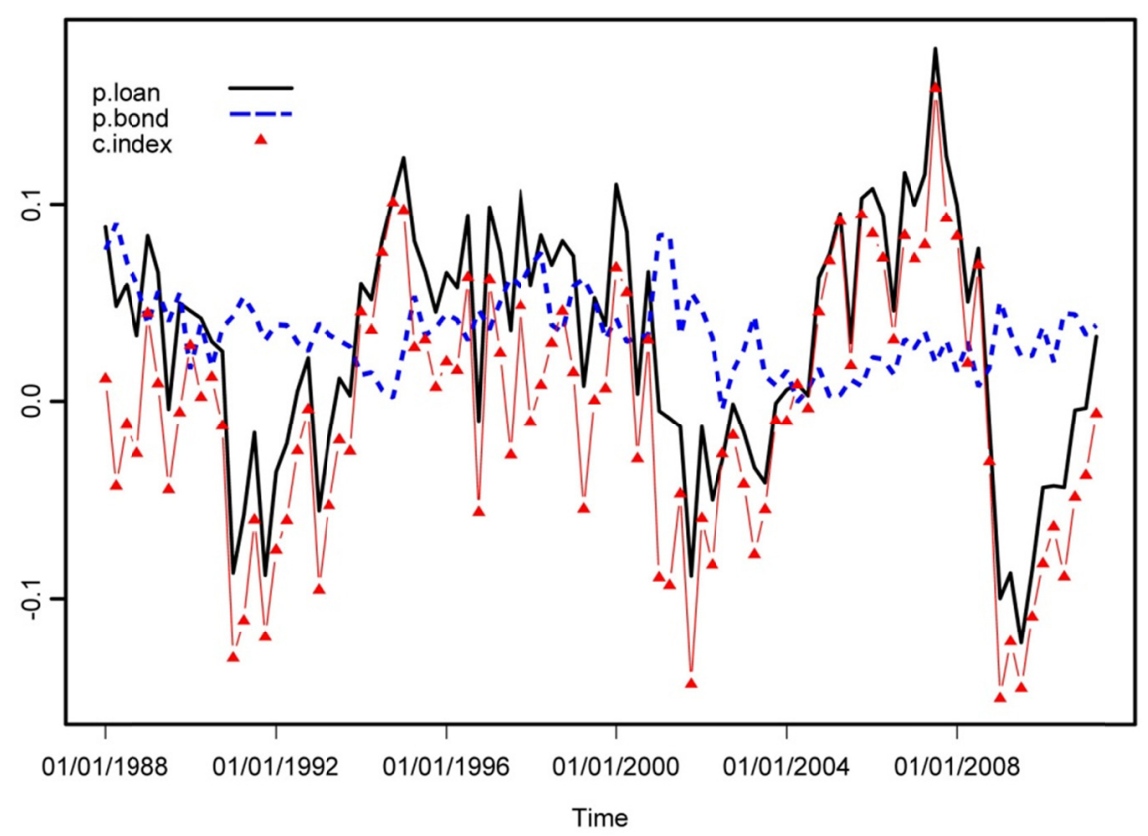

Figure 2. The Percentage Change of Bonds, Loans and the Credit Index

\section{Empirical Results: U.S. Responses}

As outlined in the previous sections we have two policy variables, namely ffr and u.ffr, and three financial market measures: BL percentage change, the c.index, and SP500 percentage change. The first two financial market measures are indicators of the credit market situation and, thus, represent the credit channel.The third financial market measure indicates pseudo Tobin's q model. In the BVAR model, we order our variables in the following manner: unemployment $\rightarrow$ inflation $\rightarrow$ policy variable $\rightarrow$ financial variables. This ordering implies that the variables on the left side of the arrow (i.e. $\rightarrow$ ) affect the contemporaneous values of those on the right side of the arrow but not vice-versa.Thus, the shock to unemployment at time $t$ affects inflation, funds rate, and bank loan/SP500 at the same time period, etc., but the shock of funds rate does not affect the contemporaneous unemployment and inflation values.Note that this kind of ordering is consistent with typical assumptions in the literature (Bernanke and Blinder, 1992; Christiano, Eichenbaum and Evans, 1999, 2005) that the unemployment rate and inflation do not respond contemporaneously to a monetary shock.

In using BVAR, it is necessary to choose the prior.In the Sim-Zha Bayesian model, one set of the priors used was $\lambda_{0}=0.6, \lambda_{1}=0.1, \lambda_{2}=\lambda_{3}=1, \lambda_{4}=0.1$ (Waggoner and Zha 1998; Robertson and Tallman 2001) while the other set was $\lambda_{0}=1, \lambda_{1}=0.2, \lambda_{3}=\lambda_{4}=1$ (Sims and Zha 1998). We search the priors from the range of $\lambda_{0}=(0.6,0.8,1), \lambda_{1}=(0.1,0.2), \lambda_{3}=(0,1), \lambda_{4}=(0.1,0.25)$. There are various criteria to choose the prior.Based on the minimized root MSE criterion, the best choice for credit data is $\lambda_{0}=1, \lambda_{1}=0.2, \lambda_{3}=0, \lambda_{4}=$ 0.1 , while, for the SP500 data, the choice is $\lambda_{0}=1, \lambda_{1}=0.1, \lambda_{3}=1, \lambda_{4}=0.25$.For each hypothesis, we also run a flat prior model, i.e., the prior information is a non-dominant factor.Since the results between the specific designated prior and the flat prior models are not significantly different, we will only present the flat prior results in this paper. (Note 11)

In estimation, based on the AIC criterion, we chose lag length $p=9$.Using ffr or u.ffr as an indicator of the policy action, we estimate the responses of economic variables to policy or financial shocks in two ways: the reduced-form type impulse response function and variance decomposition. These two methods allow us to study the dynamic effects of the monetary policy on credit market measures and equity price over a long horizon, therefore providing insights about the transmission channel. 
A: IR(ffr): 1954:07-2009:03

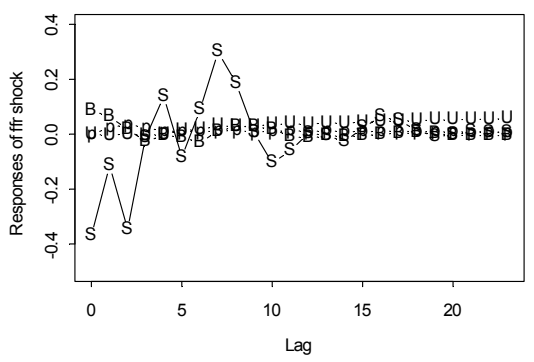

C: IR(ffr): 1987:07-2009:03

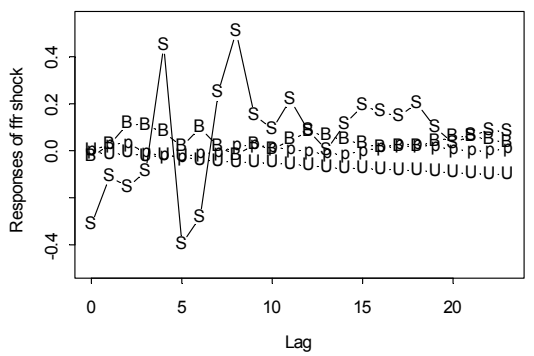

B: IR(ffr): 1954:07-1978:12

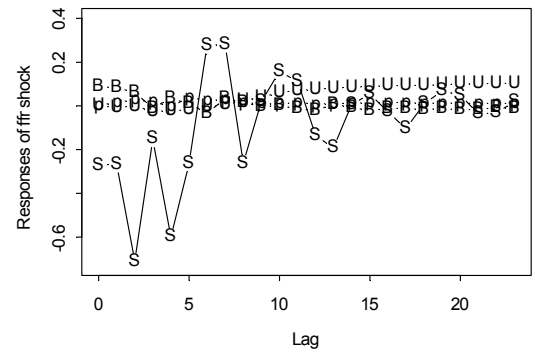

D: IR (u.ffr): 1987:07-2009:03

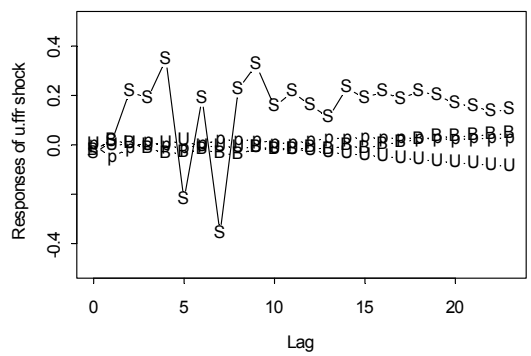

Figure 3. Responses due to a Positive Federal Funds Rate Shock: Different Time Periods

\subsection{IRF Results of a Policy Shock in the U.S.}

Figures 3A-C illustrates the impulse responses of a positive "ffr" shock on various variables in different time periods.Figure 3D shows the impulse response of a positive "u.ffr" shock on the same variables in the second sub-period.Forthe sake of clarity, we do not plot the standard errors of the impulse responses.As mentioned, the order of the variables is unemployment rate, inflation rate, policy variable and financial market measures. We include one policy variable and both financial market measures, i.e., BL and SP500, in the model.Note that the order of BL and SP500 does not matter because either variable-ordering generates similar answers.Later, as we replace BL with "c.index", the results do not change much.Thus, we only show the results of using BL." $U$ " and "p" in Figures 3A-D indicate the impulse responses of the unemployment and inflation rates respectively, while "B" and "S" represent BL and SP500 responses respectively. The responses of unemployment and inflation are basically "zero" or "flat" in all figures.As for the equity market, Figures 3A-B show that, for 1954-2009 and 1954-1978 periods, the equity price declines for the first 3-6 months following a positive ffr shock.For the second sub-period (i.e., 1987-2009), shown in Figures 3C-D, the percentage change in equity price declines in the first 3-4 months and fluctuates later due to a positive ffr shock; but the percentage change in equity price in the first 2 months is near zero for a positive u.ffr shock. (Note 12)This contradicts the existing literature that an increase in u.ffr will cause a significant decline in equity price.However, as mentioned, we use monthly data while the previous event studies use daily data.The change from high frequency to lower frequency data may be the culprit because lower frequency data may not be able to pick up the variations in the higher frequency data.As for the impact on the credit market, Figures $3 \mathrm{AB}$ show that $\mathrm{BL}$ has a modest positive change for the first two months, then goes down to zero and stays there.This kind of response may be caused by the fact that loans are contracts between banks and borrowers and it takes time for financial institutions to write or rewrite them.But Figures 3C-D, for the 1987-2009 period, indicate that the credit market actually is not responsive to shocks from either ffr or u.ffr.Thus, compared with the first sub-period (1954-1978), the role of the funds rate has obviously changed in the second period (1987-2009). 
A1: IR(BL):1954:07-2009:03

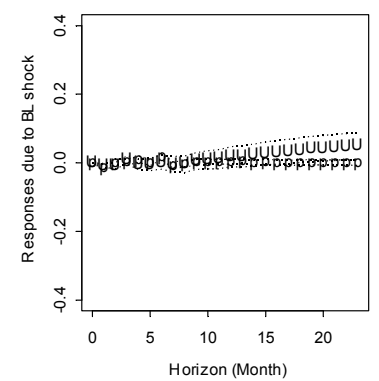

A2: IR(c.index):1954:07-2009:03

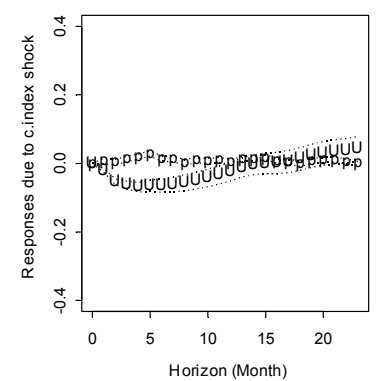

$B 1: \operatorname{R}(B L): 1954: 07-1978: 12$

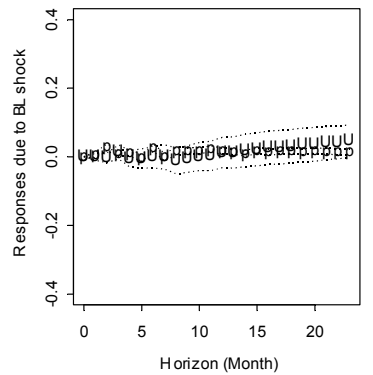

B2: IR(c.index):1954:07-1978:12

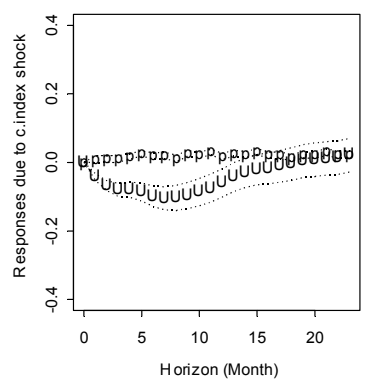

$\mathrm{C} 1: \operatorname{RR}(\mathrm{BL}): 1987: 07-2009: 03$

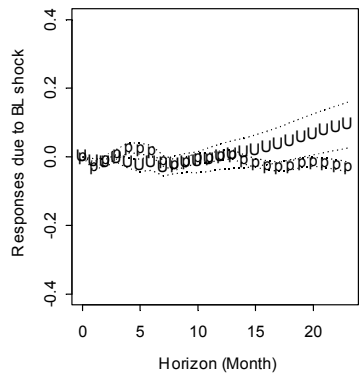

C2: IR(c.index):1987:07-2009:03

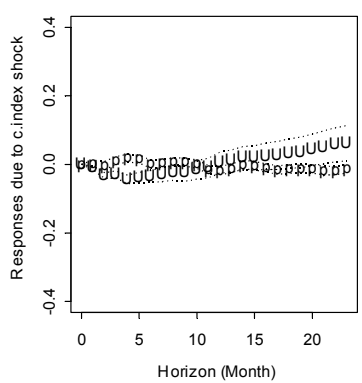

Figure 4. Responses of Unemployment and Inflation due to a Positive Credit Shock

We next investigate the relationship between the channel variables and the economy.We ask a simple question: does a positive shock to credit markets (i.e., BL/c.index) or to the SP500 affect the unemployment rate and inflation?If the answer is yes, then the Fed's recent direct lending strategy is a good remedy in rescuing the unresponsiveness of the ffr reduction policy.Figures 4 and 5 offer a glimpse of the answer.There is a clear difference between these two channels.Figures 4A1-C1 track the responses of unemployment (U) and inflation (p) due to one positive standard deviation shock on BL.Figures 4A2-C2 indicate the responses due to a positive shock to c.index. The dashed lines are the standard errors of the responses.In Figures 4A1-C1, the unemployment rate does not respond downward and the inflation response is basically zero for all three different time periods; however, Figures 4A2-C2 tell a different story.Obviously, the unemployment rate declines when a positive shock to c.index occurs.As mentioned, c.index is the difference between the percentage change of bank loans and the percentage of corporate bonds, and a positive shock to c.index implies a positive injection of credits to small firms (i.e., firms that are unable to issue bonds). The results of Figures 4A2-C2 support the notion of the financial accelerator model that small firms' credit availability matters. This also justifies the Fed's direct lending monetary policy action during the 2008 crisis.However, we should note that the magnitude of unemployment reduction is much smaller in the second sub-period than that of the first sub-period.It implies that the financial accelerator mechanism is stronger in the first sub-period than the second sub-period.As for the equity market, a positive SP500 shock in Figure 5 significantly lowers the unemployment rate after 4-5 months. However, the response of inflation to the stock market shock is basically around zero. 
A: Whole period: 1954:07-2009:03

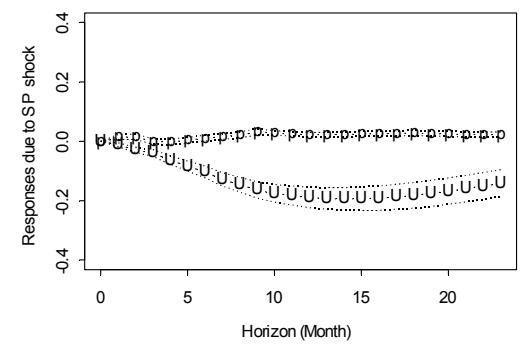

C: Sub-period-2: 1987:07-2009:03

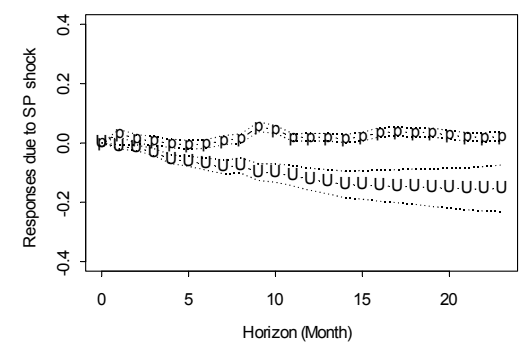

B: Sub-period-1: 1954:07-1978:12

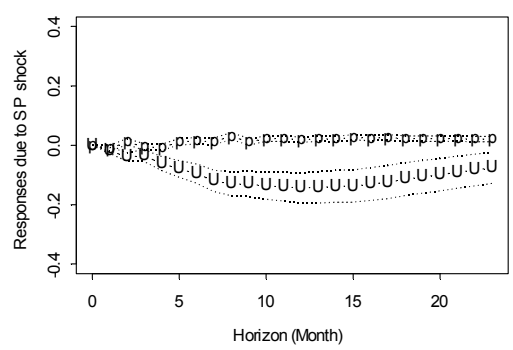

Figure 5. Responses of Unemployment and Inflation due to a Positive SP 500 Shock

\subsection{Policy Reaction Function and the Reciprocal Macro Effects}

We showed in the previous section how the policy variable initially affects the credit market and the stock market, which, in turn, affect unemployment and inflation.In this section, we will examine this relationship from a different perspective. We first ask how a shock to each of the two macro variables affects the funds rate, the so called policy reaction function.For instance, the Fed may deliberately raise the interest rate to fight inflation or lower the interest rate to curb recession. This type of policy reaction could vary from cycle to cycle in both magnitude and speed.To see whether the equity channel or the credit channel have stronger effects, we include credit market and equity market measures separately in each respective BVAR model.Figures 6 and 7 show the implied response functions of the fed funds rate to shocks of unemployment and inflation, respectively.In both figures, "E" indicates the response from the equity channel and "B" is from the credit channel.Figures 6A-B shows that, given a positive shock to unemployment, the Federal Reserve responds with an easy money policy by lowering the funds rate for almost a year before its gradual return to the long run equilibrium.Figure $6 \mathrm{C}$ indicates that it takes longer time periods for ffr to go downward and then upward.This pattern of response is true for both models except that the credit channel shows a stronger reaction to the Fed for the whole time period and the first sub-period.In the case ofa positive inflation shock, Figures 7A-B provide expected results that the Fed would pursue a tightening monetary policy and push up the funds rate. The peak effect comes after 8 to 9 months.Figure 7C shows a peculiar result that, for the period of 1987:07 to 2009:03, the ffr declines slowly after a positive inflation shock.This counter-intuitive result again supports our previous findings that the role of the funds rate has obviously changed in this second sub-period.In addition, the period of 1987:07-2009:03 is a period of low inflation, i.e., the period of great moderation. 
A: Whole period: 1954:07-2009:03

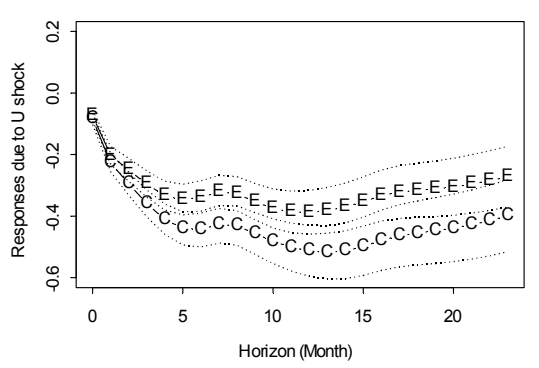

C: Sub-period-2: 1987:07-2009:03

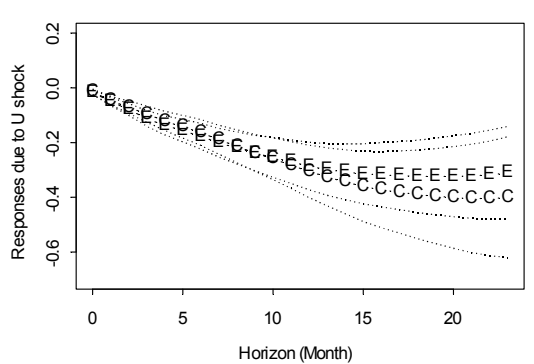

B: Sub-period-1: 1954:07-1978:12

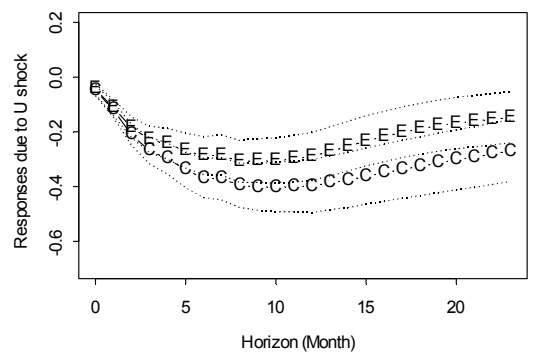

Figure 6. Responses of Funds Rate to Unemployment Shock

A; Whole period: 1954:07-2009:03

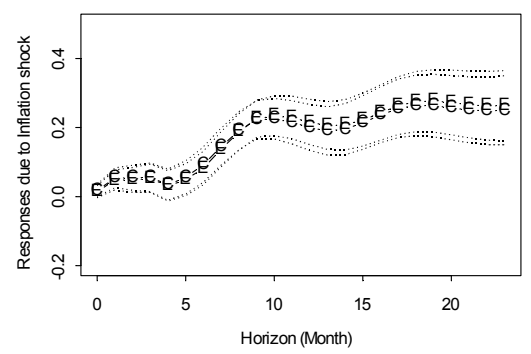

C: Sub-period-2: 1987:07-2009:03

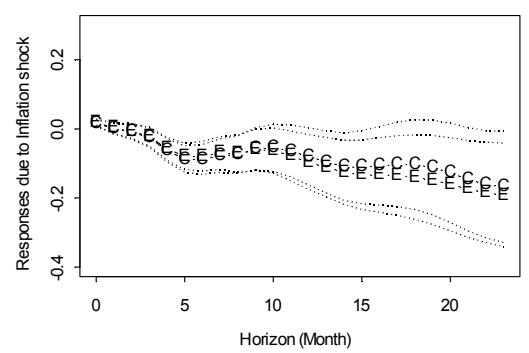

B: Sub-period-1: 1954:07-1978:12

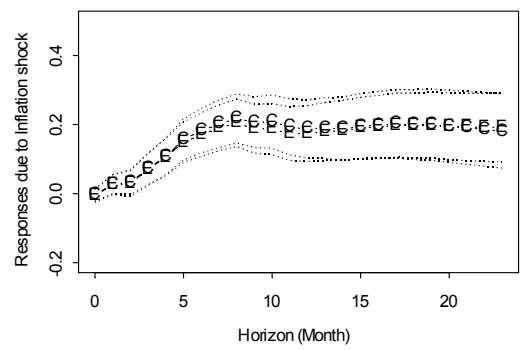

Figure 7. Responses of Funds Rate to Inflation Shock

\subsection{Variance Decomposition}

So far, we have obtained various results from the impulse response functions.In equation (2), the coefficients $\mathrm{A}_{0}$ and $\mathrm{F}$ measure the direct effect of shocks in one variable on another.To measure the total (direct and indirect) effect of such shocks, we need to use the variance decomposition technique.In this section, we order the variables in a similar sequence, i.e., unemployment, inflation, funds rate, BL, SP500, to diagnose the contribution of the various shocks on a specific forecast error variance. (Note 13) 
Table 1. Comparison of Variance Decompositions for Different Sample Periods

\begin{tabular}{|c|c|c|c|c|c|c|c|c|c|c|}
\hline Panel A & & & & & & & & & & \\
\hline \multirow{4}{*}{$\begin{array}{l}\text { Forecasted } \\
\text { variable }\end{array}$} & \multicolumn{10}{|c|}{ Source of Shock, by Period } \\
\hline & \multicolumn{2}{|l|}{ U Rate } & \multicolumn{2}{|l|}{ Inflation } & \multicolumn{2}{|l|}{$\begin{array}{l}\text { ffr } \\
\text { (u.ffr) }\end{array}$} & \multicolumn{2}{|l|}{ BL } & \multicolumn{2}{|l|}{ SP500 } \\
\hline & $54-78$ & 5400 & $54-78$ & 5400 & $54-78$ & 5400 & $54-78$ & 5400 & $54-78$ & \\
\hline & $87-09$ & $34-09$ & 87-09 & 34-09 & $87-09$ & 34-09 & $87-09$ & 34-09 & $87-09$ & $34-09$ \\
\hline \multirow[t]{3}{*}{ U Rate } & 0.73 & & 0.00 & & 0.08 & & 0.00 & & 0.18 & \\
\hline & 0.61 & 0.59 & 0.07 & 0.02 & 0.06 & 0.02 & 0.05 & 0.01 & 0.21 & 0.35 \\
\hline & $(0.70)$ & & $(0.05)$ & & $(0.02)$ & & $(0.02)$ & & $(0.21)$ & \\
\hline \multirow[t]{3}{*}{ Inflation } & 0.09 & & 0.58 & & 0.09 & & 0.12 & & 0.12 & \\
\hline & 0.17 & 0.11 & 0.56 & 0.73 & 0.05 & 0.04 & 0.08 & 0.01 & 0.13 & 0.11 \\
\hline & $(0.15)$ & & $(0.59)$ & & $(0.11)$ & & $(0.07)$ & & $(0.08)$ & \\
\hline ffr & 0.26 & & 0.10 & & 0.29 & & 0.13 & & 0.22 & \\
\hline \multirow[t]{2}{*}{ (u.ffr) } & 0.27 & 0.28 & 0.07 & 0.12 & 0.62 & 0.27 & 0.01 & 0.02 & 0.03 & 0.31 \\
\hline & $(0.12)$ & & $(0.18)$ & & $(0.54)$ & & $(0.11)$ & & $(0.05)$ & \\
\hline \multirow[t]{3}{*}{ BL } & 0.14 & & 0.05 & & 0.04 & & 0.68 & & 0.09 & \\
\hline & 0.21 & 0.12 & 0.06 & 0.03 & 0.09 & 0.02 & 0.49 & 0.67 & 0.16 & 0.15 \\
\hline & $(0.29)$ & & $(0.07)$ & & $(0.02)$ & & $(0.45)$ & & $(0.17)$ & \\
\hline \multirow[t]{3}{*}{ SP500 } & 0.05 & & 0.06 & & 0.08 & & 0.05 & & 0.76 & \\
\hline & 0.02 & 0.02 & 0.04 & 0.02 & 0.06 & 0.02 & 0.03 & 0.00 & 0.86 & 0.93 \\
\hline & $(0.04)$ & & $(0.04)$ & & $(0.05)$ & & $(0.02)$ & & $(0.85)$ & \\
\hline \multicolumn{11}{|l|}{ Panel B } \\
\hline \multirow{4}{*}{$\begin{array}{l}\text { Forecasted } \\
\text { variable }\end{array}$} & \multicolumn{10}{|c|}{ Source of Shock, by Period } \\
\hline & \multicolumn{2}{|l|}{ U Rate } & \multicolumn{2}{|l|}{ Inflation } & $\begin{array}{l}\text { ffr } \\
\text { (u.ffr) }\end{array}$ & & \multicolumn{2}{|l|}{ c.index } & \multicolumn{2}{|l|}{ SP500 } \\
\hline & $54-78$ & 5400 & $54-78$ & 5400 & $54-78$ & 5400 & $54-78$ & 5400 & $54-78$ & 5400 \\
\hline & $87-09$ & 54-09 & $87-09$ & 34-09 & $87-09$ & 54-09 & $87-09$ & 54-09 & $87-09$ & 34-09 \\
\hline \multirow[t]{3}{*}{ U Rate } & 0.71 & & 0.00 & & 0.05 & & 0.07 & & 0.17 & \\
\hline & 0.61 & 0.60 & 0.08 & 0.02 & 0.12 & 0.02 & 0.03 & 0.02 & 0.15 & 0.34 \\
\hline & $(0.76)$ & & $(0.04)$ & & $(0.01)$ & & $(0.01)$ & & $(0.19)$ & \\
\hline \multirow[t]{3}{*}{ Inflation } & 0.05 & & 0.60 & & 0.08 & & 0.13 & & 0.14 & \\
\hline & 0.16 & 0.09 & 0.62 & 0.73 & 0.07 & 0.04 & 0.04 & 0.02 & 0.11 & 0.11 \\
\hline & $(0.17)$ & & $(0.65)$ & & $(0.09)$ & & $(0.02)$ & & $(0.07)$ & \\
\hline ffr & 0.13 & & 0.12 & & 0.26 & & 0.25 & & 0.25 & \\
\hline \multirow[t]{2}{*}{ (u.ffr) } & 0.26 & 0.21 & 0.07 & 0.11 & 0.65 & 0.29 & 0.01 & 0.08 & 0.02 & 0.31 \\
\hline & $(0.13)$ & & $(0.18)$ & & $(0.61)$ & & $(0.4)$ & & $(0.04)$ & \\
\hline \multirow[t]{3}{*}{ c.index } & 0.11 & & 0.03 & & 0.07 & & 0.68 & & 0.12 & \\
\hline & 0.20 & 0.10 & 0.10 & 0.02 & 0.11 & 0.02 & 0.48 & 0.69 & 0.11 & 0.17 \\
\hline & $(0.33)$ & & $(0.06)$ & & $(0.02)$ & & $(0.44)$ & & $(0.14)$ & \\
\hline \multirow[t]{3}{*}{ SP500 } & 0.04 & & 0.06 & & 0.08 & & 0.03 & & 0.78 & \\
\hline & 0.02 & 0.02 & 0.03 & 0.02 & 0.06 & 0.02 & 0.04 & 0.01 & 0.85 & 0.92 \\
\hline & $(0.05)$ & & $(0.03)$ & & $(0.05)$ & & $(0.02)$ & & $(0.85)$ & \\
\hline
\end{tabular}


The values in Table 1A-B are at the $24^{\text {th }}$ forecasting time horizon; panel A uses BL and panel B uses c.index as the credit measure.Each row of Table 1 represents the percentage of the variance of the forecasted variable accounted for by shocks to the variables listed on the top of each column over a 24-month horizon.Each cell has four numbers: three numbers without parentheses and one number with parenthesis. The three numbers without parentheses represent the results from the time periods of 1954:07-1978:12 (54-78), 1987:07-2009:03 (87-09), and 1954:07 to 2009:03 (54-09), respectively.The one number with parenthesis in each cell is the variance decomposition result of the period 1987:07-2009:03 (87-09) when ffr is replaced by u.ffr.

The percentage of variances explained by shocks to various variables appears to be somewhat sensitive to the selection of the sample period.There are three sets of numbers that are bolded in this table that deserve our attention. The first set is 0.29 and 0.62 where funds rate shock itself contributes $29 \%$ to the variance of funds rate forecast error in the 54-78 period and that increases to $62 \%$ in the $87-09$ period.Thus, the volatility of the funds rate is affected more by itself in the 87-09 period.In addition, inflation and unemployment rate shocks contribute $10 \%$ and $26 \%$ in the $54-78$ period respectively; but the contribution of inflation drops to $7 \%$ while the unemployment contribution stays at $27 \%$ in the $87-09$ period.Thus, unemployment is still an important element in explaining the variation of the funds rate in the 87-09 period, while the inflation rate is less important.The second set is 0.68 and 0.49 where the contribution of the credit market shock (BL) to the variance of BL forecast error decreases from $68 \%$ to $49 \%$.Even so, the contribution of the unemployment shock to this variance increases from $14 \%$ in the $54-78$ period to $21 \%$ in the $87-09$ period.Thus, unemployment has become more important to the variation of the BL in the 87-09 period.The third set is 0.76 and 0.86 where the contribution of the SP500 shock to the variance of SP500 increases from $76 \%$ in the $54-78$ period to $86 \%$ in the $87-09$ period.Thus, the equity market's volatility is affected a bit more by itself than any other policy or macro variables during the $87-09$ period.

When ffr is replaced by u.ffr in the model for the 87-09 period, most numbers are quite similar except when the forecast variable is ffr or u.ffr.In the case of u.ffr, the funds rate shock itself contributes $54 \%$ while the shocks of other variables, except the shock of equity market, contribute double digit percentages to the variance of the u.ffr forecast error.This differs from the case of ffr where unemployment rate shock is a major contributor to the variance of the ffr forecast error.

The numbers in Panel A are very similar to those in Panel B, except the third row of each panel: when the forecasted variable is ffr. When we use c.index, instead of BL, as the credit measure in the model, there is a re-allocation in the magnitudes of the sources of shocks in the 54-78 period as we decompose the variance of the forecasted error of the ffr.As one may see in the third row of panel B, c.index contributes $25 \%$ to the variance of forecasted ffr error, an obvious increase from BL's $13 \%$ in panel A.This again indicates that c.index plays a more significant role in the $54-78$ period than $\mathrm{BL}$.

\section{International Linkage}

\subsection{IRF Results}

In globally connected financial markets, U.S. policy and equity markets may well affect other countries' equity markets. We obtained the share prices of various foreign countries from IMF Financial Statistics data.Both the U.S. credit market and equity market measures are included in the model and the change of foreign share price is placed in the last position.The order between BL (or c.index) and equity price changes does not matter: either way to order these two variables generates similar results.Also, replacing BL with c.index produces approximately the same results.Thus, we will only report one set of these various results in two sub-periods.Countries included in our analysis are Canada, France, Japan, and the U.K. (Note 14)Due to data availability, the starting date of the analyzed time period differs between countries. We examine the impulse responses of the foreign share prices to a positive ffr shock.The results (not shown here) indicate that there is a fairly high degree of co-movement of U.S. and foreign equity markets over both sub-sample periods due to a positive ffr shock.Since the volatility in the U.S. equity market is mostly attributed to itself, we also examine the foreign share price responses due to the U.S. equity market shock.Figures $8 \mathrm{~A}-\mathrm{D}$ indicate the response of foreign share price to a positive SP500 shock during the two sub-sample periods, with "1" indicating the period of 1960:02-1978:12 and "2" indicating the period of 1987:07-2009:03. (Note 15) 


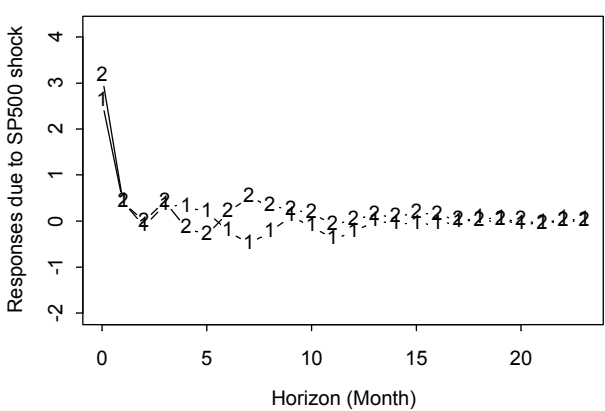

C: Japan Equity Responses in Two Periods

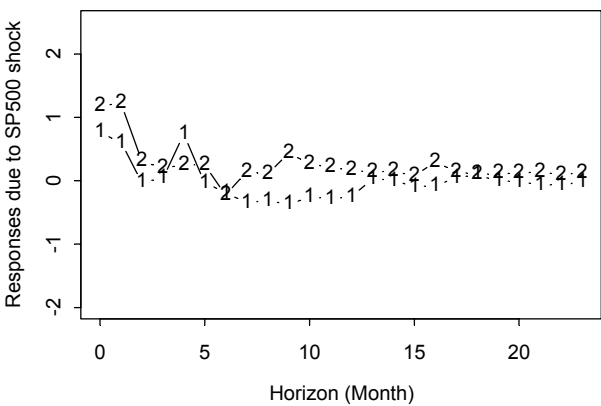

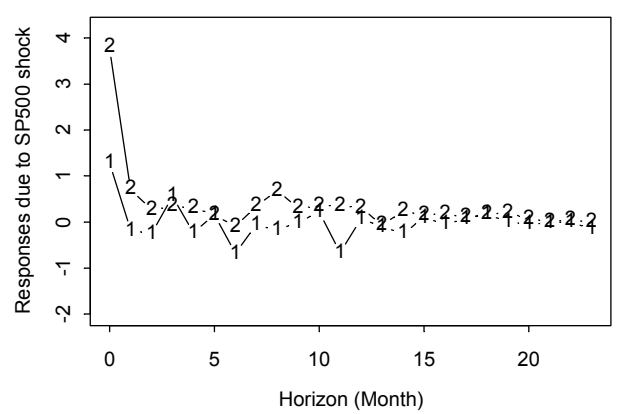

D: UK Equity Responses in Two Periods

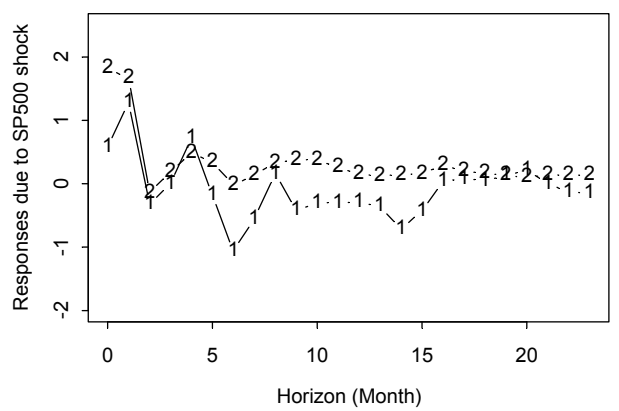

Figure 8. Different Equity Price Responses due to a Positive U.S. Equity Shock

There are two interesting findings from the IRFs of the four nations.First, foreign share prices move in the same direction and magnitude as the U.S. share price due to a funds rate shock.As with the U.S. equity price, the response of foreign stock prices due to a positive funds rate shock is much less in the second period than that of the first period.Second, foreign share prices move upward due to a positive shock in the U.S. share price.The responses occur mostly in the first 2 months.Furthermore, the responses of foreign share prices in the second period is stronger than that of the first period, suggesting a more globalized financial integration in the later period.

\subsection{Variance Decomposition}

To calculate the variance decomposition in a VAR model, we order the variables in the following manner: unemployment $\rightarrow$ inflation $\rightarrow$ federal funds rate $\rightarrow$ BL $\rightarrow$ SP $500 \rightarrow$ S-other (i.e., foreign country share price). (Note 16) Table 2 shows the variance decomposition of various BVAR models where each model includes a foreign country's equity price (i.e., a specific country's S-other). Since the focus is on the equity market, we decompose the variances of two forecasted variables: SP500 and S-other.The values in Table 2 are at the $24^{\text {th }}$ forecasting time horizon. There are two sub-sample periods for each country so we mayevaluate the possible impact of a greater globalization in recent time period.An additional row is added to each country to report the variance decomposition for the 87-09 period when ffr is replaced by u.ffr.

Regardless of the country involved, there are four general patterns in the results. First, the U.S. equity market is not affected much by the foreign market. In Table 2, when the forecasted variable is SP500, the contribution of S-other to the variance of SP500 is small. For example, in the time periods of 1957-1978 (i.e., 57-78) and 1987-2009 (i.e., 87-09), Canada's (France, Japan, the U.K.) equity market contributed 0.014 and 0.061 (0.027 and $0.022,0.040$ and $0.025,0.052$ and 0.038 ) respectively. Second, the U.S. equity market has strong impacts on foreign equity markets. When the forecasted variable is S-other, the contribution of SP500 to the variance of S-other is not trivial. In the periods of 57-78 and 87-09, SP500 contributed 0.438 and 0.521 ( 0.089 and 0.457 , 0.082 and $0.120,0.155$ and 0.396 ) to the share price of Canada (France, Japan, the U.K.). Third, the impacts of U.S. equity market on foreign equity markets are stronger in the 87-09 period than those in the 57-78period. As in Table 2, $0.521(0.457,0.120,0.396)$ is greater than $0.438(0.089,0.082,0.155)$ in Canada (France, Japan, the U.K.). The results clearly indicate a greater integration of the U.S and foreign equity markets. Fourth, when u.ffr replaces ffr in the model, the results are very similar, even though the impacts of the U.S. equity market on 
foreign equity markets becomes slightly stronger. For France, Japan and the U.K., the contribution of SP500 on the variance of the forecast error of S-other becomes $(0.465,0.148,0.452)$ instead of $(0.457,0.120,0.396)$.

Table 2. Variance Decomposition Including a Foreign Country

\begin{tabular}{|c|c|c|c|c|c|c|c|c|}
\hline & \multirow{2}{*}{$\begin{array}{l}\text { Time } \\
\text { Period }\end{array}$} & \multirow{2}{*}{$\begin{array}{l}\text { Forecasted } \\
\text { Variable }\end{array}$} & \multicolumn{6}{|c|}{ Source of Shock } \\
\hline & & & U Rate & Inflation & $\begin{array}{l}\text { ffr } \\
\text { (u.ffr) }\end{array}$ & BL & SP500 & S-Other \\
\hline \multirow[t]{6}{*}{ Can } & \multirow{2}{*}{$57-78$} & SP500 & 0.040 & 0.069 & 0.082 & 0.043 & 0.752 & 0.014 \\
\hline & & S-other & 0.051 & 0.072 & 0.067 & 0.036 & 0.438 & 0.335 \\
\hline & \multirow{2}{*}{$87-09$} & SP500 & 0.023 & 0.036 & 0.084 & 0.023 & 0.774 & 0.061 \\
\hline & & S-other & 0.035 & 0.045 & 0.045 & 0.025 & 0.521 & 0.330 \\
\hline & $87-09$ & SP500 & $(0.057)$ & $(0.039)$ & $(0.049)$ & $(0.016)$ & $(0.779)$ & $(0.059)$ \\
\hline & (u.ffr) & S-other & $(0.057)$ & $(0.048)$ & $(0.032)$ & $(0.024)$ & $(0.524)$ & $(0.316)$ \\
\hline \multirow[t]{6}{*}{ Fra } & \multirow{2}{*}{$60-78$} & SP500 & 0.043 & 0.072 & 0.101 & 0.052 & 0.705 & 0.027 \\
\hline & & S-other & 0.045 & 0.070 & 0.080 & 0.054 & 0.089 & 0.663 \\
\hline & \multirow{2}{*}{$87-09$} & SP500 & 0.018 & 0.035 & 0.061 & 0.036 & 0.828 & 0.022 \\
\hline & & S-other & 0.034 & 0.035 & 0.034 & 0.016 & 0.457 & 0.424 \\
\hline & $87-09$ & SP500 & $(0.046)$ & $(0.034)$ & $(0.058)$ & $(0.023)$ & $(0.812)$ & $(0.027)$ \\
\hline & (u.ffr) & S-other & $(0.057)$ & $(0.036)$ & $(0.018)$ & $(0.015)$ & $(0.465)$ & $(0.410)$ \\
\hline \multirow[t]{6}{*}{ Jap } & \multirow{2}{*}{$60-78$} & SP500 & 0.048 & 0.078 & 0.093 & 0.056 & 0.686 & 0.040 \\
\hline & & S-other & 0.038 & 0.066 & 0.055 & 0.080 & 0.082 & 0.678 \\
\hline & \multirow{2}{*}{$87-09$} & SP500 & 0.030 & 0.035 & 0.052 & 0.030 & 0.828 & 0.025 \\
\hline & & S-other & 0.027 & 0.049 & 0.053 & 0.055 & 0.120 & 0.696 \\
\hline & $87-09$ & SP500 & $(0.055)$ & $(0.039)$ & $(0.044)$ & $(0.024)$ & $(0.819)$ & $(0.019)$ \\
\hline & (u.ffr) & S-other & $(0.056)$ & $(0.041)$ & $(0.037)$ & $(0.057)$ & $(0.148)$ & $(0.661)$ \\
\hline \multirow[t]{6}{*}{ UK } & \multirow{2}{*}{$63-78$} & SP500 & 0.074 & 0.078 & 0.146 & 0.063 & 0.587 & 0.052 \\
\hline & & S-other & 0.086 & 0.060 & 0.156 & 0.049 & 0.155 & 0.494 \\
\hline & \multirow{2}{*}{ 87-09 } & SP500 & 0.021 & 0.034 & 0.058 & 0.031 & 0.818 & 0.038 \\
\hline & & S-other & 0.025 & 0.053 & 0.056 & 0.034 & 0.396 & 0.436 \\
\hline & $87-09$ & SP500 & $(0.046)$ & $(0.039)$ & $(0.047)$ & $(0.020)$ & $(0.821)$ & $(0.028)$ \\
\hline & (u.ffr) & S-other & $(0.047)$ & $(0.058)$ & $(0.015)$ & $(0.028)$ & $(0.452)$ & $(0.400)$ \\
\hline
\end{tabular}

\section{Conclusion}

This paper uses monthly U.S. data from 1954:07-2009:03 in a BVAR model to evaluate possible impacts of various shocks through different channels. By applying IRF and variance decomposition, we may summarize our results as the following. (1) A funds rate shock has a slightly stronger impact on equity price than on bank loans. However, the shock does not have an impact on inflation. Though it has a minor impact on unemployment in the long run, the shock does not affect unemployment in the short run. In general, most variables are not very responsive to the ffr shock in the second sub-period (87-09), comparing to those of the 54-78 period. Furthermore, a positive (negative) u.ffr shock does not depress (stimulate) the equity market in the short run. (2) We evaluate shocks in the financial market through either the credit market or the equity market. The shock in the credit market is measured in two ways: BL and c. index. A positive shock on BL has no impacts on inflation and the unemployment rate. However, a positive shock to c.index has a negative impact on unemployment but the inflation rate is not affected. The negative short-run impact on the unemployment rate is much stronger in the 54-78 period than in the 87-09 period. As for a positive equity price shock, the unemployment rate decreases in the long run but inflation rate is not affected. (3) A positive unemployment rate shock causes the funds rate to go 
down for all three time periods. A positive inflation shock induces the federal funds rate to move up in the 54-78 period, but not in the 87-09 period. (4) As for the global equity markets, a U.S. equity price shock affects foreign equity prices, more strongly so in the 87-09 period than in the 57-78 period. This indicates a stronger financial integration in the 87-09 period. Shocks to foreign equity markets do not have impacts on the U.S. equity prices.

Our results provide the following assessments for the Fed's policy actions. Given that lowering the federal funds rate can only increase equity price in the short run and a positive shock in equity price affects unemployment only in the long run, this rate-reduction policy action does not provide any immediate reliefto high unemployment. Nevertheless, a positive c.index shock does have a mild negative impact onthe unemployment rate in the short run. The Fed's action of lending directly to banks does provide a gentleshort-term lift to the economy. Thus, the dual actions of lowering the federal funds rate and lending directly to banks to ensure loan availability in the economy may lower the unemployment moderately but a significant decline in unemployment rate is not seen, especially in the short run. However, having said so, we do need to give the Fed credit in restoring the investors' confidence and stabilizing the financial system. The dual actions did provide an assurance of the Fed's willingness to resolve the financial crisis and to restore the economy, which has a positive impact on the U.S. equity market. This positive impact spreads through the global connection and provides a concrete effect on other economies.

\section{References}

Adrian, T., Paolo, C., \& Shin, H. S. (2012). Which Financial Frictions? Parsing the Evidence from the Financial Crisis of 2007-2009. ASSA meetings, Chicago, January 2012.

Bernanke, B. S., \& Blinder, A. (1992). The Federal Funds Rate and the Channels of Monetary Transmission. American Economic Review, 82(4), 901-921.

Bernanke, B. S., \& Mihov, I. (1998). Measuring Monetary Policy. Quarterly Journal of Economics, 113(3), 869-902. http://dx.doi.org/10.1162/003355398555775

Bernanke, B. S., \& Kuttner, K. N. (2005). What Explains the Stock Market's Reaction to Federal ReservePolicy? Journal of Finance, 60(3), 1221-1257. http://dx.doi.org/10.1111/j.1540-6261.2005.00760.x

Bernanke, B. S., Gertler, M., \& Gilchrist, S. (1996). The Financial Accelerator and the Flight to Quality. Review of Economics and Statistics, February, 1-15. http://dx.doi.org/10.2307/2109844

Campello, M., Graham, J. R., \& Harvey, C. R. (2010). The Real Effects of Financial Constraints:Evidence from a Financial Crisis. Journal of Financial Economics, 97(3), 470-87. http://dx.doi.org/10.1016/j.jfineco.2010.02.009

Christiano, L. J., \& Eichenbaum, M. (1992). Identification and the Liquidity Effect of a MonetaryPolicy Shock. In A. Cukierman, Z. Hercowitz, \& L. Liederman (eds.), Business Cycles, Political Economy, and Growth. Cambridge: MIT Press.

Christiano, L. J., Eichenbaum, M., \& Evans, C. L. (1999). Monetary Policy Shocks: What Have We Learned and to What End. In J. Taylor and M. Woodford (eds.), Handbook of Macroeconomics, 1A, 64-145.

Christiano, L. J., Eichenbaum, M., \& Evans, C. L. (2005). Nominal Rigidities and the Dynamic Effects of a Shock to Monetary Policy. Journal of Political Economy, 113(1), 1-45. http://dx.doi.org/10.1086/426038

Cosimano, T. F., \& Sheehan, R. G. (1994). Federal Reserve Operating Procedure 1984-1991: An Empirical Analysis. Journal of Macroeconomics, 16, 573-588. http://dx.doi.org/10.1016/0164-0704(94)90001-9

Driscoll, J. C. (2004). Does Bank Lending Affect Output? Evidence from the U.S. States. Journal of Monetary Economics, 51, 451-471. http://dx.doi.org/10.1016/j.jmoneco.2004.01.001

Ehrmann, M., \& Fratzscher, M. (2004). Taking Stock: Monetary Policy Transmission to Equity Markets. Journal of Money, Credit and Banking, 36(4), 719-737. http://dx.doi.org/10.1353/mcb.2004.0063

Gertler, M., \& Gilchrist, S. (1993). The Role of Credit Market Imperfections in the Monetary Transmission Mechanism: Arguments and Evidence. Scandinavian Journal of Economics, 1, 43-64. http://dx.doi.org/10.2307/3440134

Hubbard, R. G. (1995). Is There a Credit Channel for Monetary Policy? Federal Reserve Bank of St.Louis Review, May/June, 63-74.

Kashyap, A. K., \& Stein, J. (1994). Monetary Policy and Bank Lending. In Mankiw, N. G. (ed.), Monetary Policy. University of Chicago Press, Chicago, IL, 221-256. 
Kashyap, A. K., \& Stein, J. (2000). What Do a Million Observations on Banks Say About the Transmission of Monetary Policy. American Economic Review, 90(3), 407-428. http://dx.doi.org/10.1257/aer.90.3.407

Konrad, E. (2009). The Impact of Monetary Policy Surprises on Asset Return Volatility: the Case of Germany. Journal Financial Markets and Portfolio Management, 23, 111-135. http://dx.doi.org/10.1007/s11408-009-0102-5

Kuttner, K. N. (2001). Monetary Policy Surprises and Interest Rates: Evidence from the Fed Funds Futures Market. Journal of Monetary Economics, 47(3), 523-44. http://dx.doi.org/10.1016/S0304-3932(01)00055-1

Oliner, S. D., \& Rudebusch, G. D. (1996). Monetary Policy and Credit Conditions: Evidence from the Composition of External Finance: Comment. American Economic Review, 86(1), 300 - 309.

Robertson, J. C., \& Tallman, E. (2001). Improving Federal-Funds Rate Forecasts in VAR Models Used for Policy Analysis. Journal of Business and Economic Statistics, 19(3), 324-30. http://dx.doi.org/10.1198/073500101681019972

Sims, C. A., \& Zha, T. (1998). Bayesian Methods for Dynamic Multivariate Models. International Economic Review, 39(4), 949-968. http://dx.doi.org/10.2307/2527347

Strongin, S. (1995). The Identification of Monetary Policy Disturbances: Explaining theLiquidity Puzzle. Journal of Monetary Economics, 35(3), 463-497. http://dx.doi.org/10.1016/0304-3932(95)01197-V

Tobin, J. (1969). A General Equilibrium Approach to Monetary Theory. Journal of Money Credit and Banking, l(1), 15-29. http://dx.doi.org/10.2307/1991374

Vijverberg, C. C. (2004). An Empirical Financial Accelerator Model: Small Firms' Investment and Credit Rationing. Journal of Macroeconomics, 26, 101-129. http://dx.doi.org/10.1016/j.jmacro.2002.09.004

Waggoner, D. F., \& Zha, T. (2003). Likelihood Preserving Normalization in Multiple Equation Models.Journal of Econometrics, 114(2), 329-347. http://dx.doi.org/10.1016/S0304-4076(03)00087-3

\section{Notes}

Note 1. FDIC Press Release (various issues).

Note 2. "Stocks Jump on Bernanke Comments." The Wall Street Journal, March 27, 2012: C4.

Note 3. We will not use q, defined as the market value of firms divided by the replacement cost of capital, in our analysis. Rather, we will use the stock market indicator to link the relationship between the monetary policy and investment. Tobin's q was tested mostly at the manufacturing firm level. Under the assumption of price rigidity for capital input, stock price changes should be a good proxy for changes in $\mathrm{q}$.

Note 4. Note that the prior is also the drawback of the Bayesian model from the Bayesian critics' point of view.

Note 5. According to Sims and Zha (1998), these hyper-parameters specified in the prior have the following implications. The parameter imposes an overall tightness across the elements of the prior on the reduced form variance. A smaller implies a tighter overall prior. is related to the standard deviation around $\mathrm{F}$. The term indicates how the variance shrinks as the lag length increases. The variance of the constant term in the model has a prior variance of. Since our model does not consider other exogenous or dummy variables, we will not consider additional parameters relating to the priors.

Note 6. The St. Louis Fed set at five different rates, i.e., percent, and calculated the implied FFR for each case. was set at $2 \%$ before April 2000 and it was changed to $2.5 \%$ in later periods.

Note 7. This is calculated as the average daily target federal funds rate over the month.

Note 8. Adrian, Colla and Shin (2012) also mentioned the different patterns of loans and bonds in economic recession times.

Note 9. Since the federal funds rate is available after July 1954, our data will be from July 1954 to March 2009.

Note 10. The reasons for having such a gap between the first and the second sub-periods are the following. First, according to Thornton (2006), even though the FOMC returned to a funds rate operating procedure in September 1982 effectively, the FOMC stated officially that it was targeting borrowed reserves. Thus, for quite a period of time, it was not clear to what extent that the FOMC was targeting the funds rate. Second, as mentioned earlier, u.ffr is a valid construction during the period of 1987:7 - 2009:3.

Note 11. This is not unusual: if the specific prior has a peak in the density function that is close to that of the likelihood function, the flat prior will generate similar results as those of the specific prior. 
Note 12. Note that Konrad (2009) used the Taylor rule for the case of Germany.

Note 13. Note that in this model, we put both bank loan and SP500 in the same model. When we change the ordering of the bank loan and SP500, the results are similar. Thus, the variance decomposition results with SP500 preceding bank loan are not presented.

Note 14. Germany is not included because of its reunification in 1989.

Note 15. For France and Japan, the first sub-period is 1960:02 to 1978:12 while for Canada and the U.K. the first sub-period starts from 1957:2 and 1963:2 respectively.

Note 16. The results are very similar if we include BL or do not include BL. If we replace BL with c.index, the results are not much different. 